\title{
Analisis Kemampuan Pemecahan Masalah Matematis Siswa Kelas IX MTs Dalam Menyelesaikan Soal Model PISA Pada Konten Perubahan dan Hubungan
}

\author{
Dimas Vajar Oktaviana ${ }^{1)}$, Syafrimen ${ }^{2)}$, Riski Wahyu Yunian Putra ${ }^{3)}$ \\ ${ }^{1)}$ Universitas Islam Negeri (UIN) Raden Intan Lampung. J1 Hasan 1 no.1 Korpri Bandar Lampung; \\ dimashimatikaa@gmail.com syafrimens@yahoo.com rizkiputra8916@yahoo.com
}

\begin{abstract}
Abstrak
Penelitian ini bertujuan untuk menganalisis kemampuan pemecahan masalah siswa kelas VIII MTs Hasanuddin dalam menyelesaikan soal model PISA pada konten perubahan dan hubungan. Penelitian ini adalah penelitian kualitatif dengan pendekatan deskriptif kualitatif. Subjek penelitian ditentukan melalui purposive sampling dan didasarkan dari tingkat kemampuan pemecahan masalah siswa, yaitu tinggi, sedang, dan rendah. Subjek yang diambil untuk penelitian ini berjumlah 3 orang. Teknik pengumpulan data dilakukan dengan tes pemecahan masalah dan wawancara. Teknik keabsahan data yang dilakukan pada penelitian ini adalah metode triangulasi. Teknik analisis data yang digunakan yaitu reduksi data, menyajikan data, dan menarik kesimpulan. Berdasarkan analisis diperoleh kesimpulan bahwa 1) siswa dengan kemampuan pemecahan masalah tinggi lebih dapat memahami soal yang diberikan dan menjawab semua pertanyaan dengan baik dan benar, 2) siswa dengan kemampuan pemecahan masalah sedang menjawab dengan benar hanya saja ia kurang teliti ketika tidak memberikan kesimpulan dan dalam beberapa soal ia tidak mem berikan informasi-informasi yang ada pada soal, 3) siswa yang memiliki kemampuan pemecahan rendah cendrung ingin menjawab pertanyaan dengan cepat sehingga tidak menuliskan informasi yang ada pada soal dan tidak teliti ketika mengerjakan soal sehingga menyebabkan kesalahan ketika menjawab soal.
\end{abstract}

Kata Kunci : Kemampuan pemecahan masalah, PISA, Soal-Soal PISA, Perubahan dan Hubungan

\begin{abstract}
The aims of this study is to analyze the problem solving ability of grade VIII students MTs Hasanuddin in solving the problem of PISA model on content of changes and relationships. This research is qualitative research with qualitative descriptive approach. Research subjects were determined by purposive sampling and were based on the students' problem solving ability, ie high, medium, and low. Subjects taken for this study amounted to 3 people. Data collection techniques were conducted with problem-solving and interviewing tests. The technique of data validity done in this research is triangulation method. Data analysis techniques used are reducing data, presenting data, and draw conclusions. Based on analysis of data the conclusion is that: 1) The students with high problem solving ability can better understand the given problem and answer all questions well and correctly, 2) The student with problem-solving ability is answering correctly but it is not so rigorous when it does not give a conclusion and in some questions it does not provide any information on the matter, 3) The students who have the ability to solve the low tends to answer the question quickly so as not to write down the information that is on the problem and not careful when working on the problem causing errors when answering questions.
\end{abstract}

Key Words: Problem Solving Ability, PISA, The Problem PISA, Changes and Relationship 


\section{PENDAHULUAN}

Kemampuan matematika siswa perlu merujuk tidak hanya untuk perhitungan dasar, tetapi juga bagaimana menggunakannya untuk menganalisis masalah yang rumit, dan untuk memperkirakan efisiensi cara yang berbeda dari pemecahan masalah yang ada dalam kehidupan (Marilyn, 2000; Smith \& Mary, 1998; Cai \& Steven; Edward \& Jinfa, 2005; Magen, 2016). Kemampuan pemecahan masalah di Indonesia dibawah rata-rata standar Internasional (OECD, 2015). Lemahnya kemampuan pemecahan masalah siswa di Indonesia disebabkan karena keaktifan siswa pada proses pembelajaran masih kurang dan siswa kurang mampu memberikan penjelasan atau argumentasi pada persoalan matematika (Mahdiansah \& Rahmawati, 2014; Mujulifah, 2015). Keterlibatan dalam pembelajaran sangat penting dalam membangun lingkungan belajar yang tepat dan hasil yang positif (Bickel, 1999; Chall, 2000; Gettinger \& Stoiber, 1999). Kegiatan belajar dan mengajar di berbagai sekolah masih didominasi oleh guru, guru menulis definisi dan teorema di papan tulis untuk membuktikannya secara berurutan, dan siswa yang belum mampu memahami yang disampaikan, mereka akan mudah merasa putus asa (Parsian, Motivate the Minds of Students in Mathematics, 2011). Tujuan pendidikan di Indonesia sekarang yaitu pemecahan masalah yang meliputi kemampuan memahami, merancang model, menyelesaikan masalah, sejalan dengan Niss yang menyatakan bahwa kemampuan pemecahan masalah terdapat dalam soal yang diujikan PISA.

\section{LANDASAN/KAJIAN TEORI}

Kemampuan pemecahan masalah adalah proses menerapkan pengetahuan yang telah diperoleh sebelumnya kedalam situasi baru yang belum dikenal. (Wardhani, .2005) Sedangkan PISA merupakan singkatan dari Programme International for Student Assesment yang merupakan suatu bentuk evaluasi kemampuan dan pengetahuan yang dirancang untuk siswa usia 15 tahun. (StaceyKaye., 2010) Dimana soal-soal yang ada di PISA mencangkup kemampuan pemecahan masalah siswa.

\section{METODOLOGI}

\section{Jenis Penelitian}

Penelitian yang digunakan ialah penelitian kualitatif. Sedangkan metode yang digunakan menggunakan metode deskriptif kualitatif, yang nantinya data penelitian berupa data tertulis atau lisan. (Budiyono, 2003).

\section{Waktu dan Tempat Penelitian}

Penelitian ini dilaksanakan di MTs Hasanuddin Teluk Betung Bandar Lampung. Waktu yang digunakan peneliti untuk mengadakan penelitian yaitu pada Semester Ganjil tahun ajaran 2017/2018.

\section{Subjek Penelitian}

Subjek penelitian ini yaitu siswa kelas IX MTs Hasanuddin 
Bandar Lampung, berjumlah 25 orang. Pemilihan subjek menggunakan teknik purposive sampling.(Limakrisna \& Supranto, 2013).

\section{Prosedur}

Prosedur penelitian yang dilaksanakan meliputi tiga tahap yaitu tahap persiapan, tahap pelaksanaan, dan tahap analisis data.

\section{Data, Intrumen, dan Teknik Pengumpulan Data}

Intrumen pada penelitian ini ialah soal tes dan peneliti itu sendiri.
Pengumpulan data menggunakan tes essay serta wawancara.

\section{Teknik Analisis Data}

Data hasil tes dan wawancara kemudian di reduksi lalu disajikan terakhir ditarik kesimpulan. Teknik validitas data yang akan digunakan yaitu triangulasi teknik.

\section{HASIL PENELITIAN DAN PEMBAHASAN}

Berdasarkan data hasil tes siswa didapatlah nilai siswa tes kemampuan pemecahan masalah model PISA dapat dilihat pada grafik dibawah ini:

Tabel 1. Daftar Nilai Tes Siswa

\begin{tabular}{|c|c|c|c|c|c|c|c|}
\hline RESPONDEN & SOAL & SOAL & SOAL & SOAL & SOAL & TOTAL & KESIMPULAN \\
\hline $\mathrm{i}$ & $\mathbf{2 . 1}$ & $\mathbf{2 . 2}$ & $\mathbf{3 . 1}$ & $\mathbf{3 . 2}$ & & \\
\hline $\mathrm{B}$ & 16 & 16 & 16 & 16 & 16 & 80 & TINGGI \\
\hline $\mathrm{C}$ & 15 & 14 & 13 & 15 & 16 & 73 & SEDANG \\
\hline $\mathrm{D}$ & 16 & 15 & 12 & 11 & 10 & 64 & SEDANG \\
\hline $\mathrm{E}$ & 13 & 14 & 16 & 12 & 14 & 69 & SEDANG \\
\hline $\mathrm{F}$ & 13 & 12 & 11 & 15 & 12 & 63 & SEDANG \\
\hline $\mathrm{G}$ & 12 & 13 & 11 & 14 & 16 & 66 & SEDANG \\
\hline $\mathrm{H}$ & 11 & 12 & 10 & 12 & 0 & 45 & RENDAH \\
\hline $\mathrm{I}$ & 13 & 16 & 16 & 16 & 16 & 77 & TINGGI \\
\hline $\mathrm{J}$ & 12 & 11 & 16 & 14 & 15 & 68 & SEDANG \\
\hline $\mathrm{K}$ & 16 & 16 & 16 & 16 & 16 & 80 & TINGGI \\
\hline $\mathrm{L}$ & 12 & 14 & 16 & 13 & 11 & 66 & SEDANG \\
\hline $\mathrm{M}$ & 11 & 13 & 14 & 11 & 16 & 65 & SEDANG \\
\hline $\mathrm{N}$ & 12 & 14 & 15 & 14 & 13 & 68 & SEDANG \\
\hline $\mathrm{O}$ & 12 & 12 & 12 & 12 & 12 & 60 & SEDANG \\
\hline $\mathrm{P}$ & 13 & 15 & 16 & 16 & 12 & 72 & SEDANG \\
\hline $\mathrm{Q}$ & 14 & 14 & 14 & 14 & 14 & 70 & SEDANG \\
\hline $\mathrm{R}$ & 15 & 15 & 16 & 14 & 13 & 73 & SEDANG \\
\hline $\mathrm{S}$ & 12 & 14 & 15 & 13 & 11 & 65 & SEDANG \\
\hline $\mathrm{T}$ & 10 & 14 & 15 & 12 & 11 & 62 & SEDANG \\
\hline $\mathrm{U}$ & 11 & 12 & 11 & 10 & 9 & 53 & RENDAH \\
\hline $\mathrm{V}$ & 12 & 13 & 11 & 12 & 14 & 62 & SEDANG \\
\hline $\mathrm{W}$ & 12 & 10 & 11 & 13 & 15 & 61 & SEDANG \\
\hline $\mathrm{X}$ & 16 & 13 & 11 & 10 & 0 & 50 & RENDAH \\
\hline $\mathrm{Y}$ & 12 & 14 & 11 & 15 & 10 & 62 & SEDANG \\
\hline
\end{tabular}


Berdasarkan table 1 diatas didapatlah nilai siswa tes kemudian diambil 3 siswa dari tingkat kemampuan pemecahan masalah yang berbeda yang didapat dari pengklasifikasian tingkat kemampuan pemecahan masalah tinggi, sedang dan rendah. Kemudian 3 siswa subjek penelitian diwawancarai mengenai tes.
Selanjutnya peneliti melakukan reduksi data, penyajian data berupa gambar atau table dan menarik kesimpulan. Setelah semua data disimpulkan maka tahap terakhir penelitian ini peneliti melakukan triangulasi data.

Tabel 2 Hasil Triangulasi dari Subjek Penelitian I

\begin{tabular}{|c|c|c|c|}
\hline $\begin{array}{l}\text { Butir } \\
\text { Soal }\end{array}$ & $\begin{array}{c}\text { Hasil Analisis } \\
\text { Tes }\end{array}$ & $\begin{array}{c}\text { Hasil Analisis } \\
\text { Wawancara }\end{array}$ & $\begin{array}{c}\text { Hasil Analisis } \\
\text { Observasi }\end{array}$ \\
\hline 1 & $\begin{array}{c}\text { Sujek sudah } \\
\text { memahami apa } \\
\text { yang dimaksud } \\
\text { dari butir soal } \\
\text { dengan baik }\end{array}$ & $\begin{array}{l}\text { Siswa sudah bisa } \\
\text { memahami } \\
\text { maksud dari } \\
\text { pertanyaan }\end{array}$ & $\begin{array}{l}\text { Siswa sudah dapat } \\
\text { menjawab } \\
\text { pertanyaan dengan } \\
\text { hasil yang benar dan } \\
\text { tepat }\end{array}$ \\
\hline 2.1 & $\begin{array}{c}\text { Sujek sudah } \\
\text { memahami apa } \\
\text { yang dimaksud } \\
\text { dari butir soal } \\
\text { dengan baik dan } \\
\text { menjawab dengan } \\
\text { benar }\end{array}$ & $\begin{array}{c}\text { Siswa sudah bisa } \\
\text { memahami } \\
\text { maksud dari } \\
\text { pertanyaan }\end{array}$ & $\begin{array}{c}\text { Ia sudah bisa } \\
\text { menggambarkan apa } \\
\text { yang dibutuhkan } \\
\text { untuk } \\
\text { mempermudahnya } \\
\text { dalam proses } \\
\text { penyelesaian }\end{array}$ \\
\hline 2.2 & $\begin{array}{c}\text { Siswa sudah } \\
\text { mengerjakan soal } \\
\text { dengan baik dan } \\
\text { benar }\end{array}$ & $\begin{array}{c}\text { Siswa sudah bisa } \\
\text { memahami } \\
\text { maksud dari } \\
\text { pertanyaan }\end{array}$ & $\begin{array}{l}\text { Siswa sudah dapat } \\
\text { menjawab } \\
\text { pertanyaan dengan } \\
\text { hasil yang benar dan } \\
\text { tepat }\end{array}$ \\
\hline 3.1 & $\begin{array}{l}\text { Subjek penelitian } \\
\text { sudah memahami } \\
\text { apa yang } \\
\text { dimaksud dari } \\
\text { soal }\end{array}$ & $\begin{array}{l}\text { Siswa sudah bisa } \\
\text { memahami } \\
\text { maksud dari } \\
\text { pertanyaan }\end{array}$ & $\begin{array}{c}\text { Ia sudah bisa } \\
\text { menggambarkan apa } \\
\text { yang dibutuhkan } \\
\text { untuk } \\
\text { mempermudahnya } \\
\text { dalam proses } \\
\text { penyelesaian }\end{array}$ \\
\hline 3.2 & $\begin{array}{c}\text { Subjek penelitian } \\
\text { sudah memahami } \\
\text { apa yang } \\
\text { dimaksud dari } \\
\text { soal }\end{array}$ & $\begin{array}{l}\text { Siswa sudah bisa } \\
\text { memahami } \\
\text { maksud dari } \\
\text { pertanyaan }\end{array}$ & $\begin{array}{l}\text { Siswa sudah dapat } \\
\text { menjawab } \\
\text { pertanyaan dengan } \\
\text { hasil yang benar dan } \\
\text { tepat }\end{array}$ \\
\hline
\end{tabular}


Tabel 3 Hasil Triangulasi dari Subjek Penelitian II

\begin{tabular}{|c|c|c|c|}
\hline $\begin{array}{c}\text { Butir } \\
\text { Soal }\end{array}$ & Hasil Analisis Tes & $\begin{array}{l}\text { Hasil Analisis } \\
\text { Wawancara }\end{array}$ & $\begin{array}{c}\text { Hasil Analisis } \\
\text { Observasi }\end{array}$ \\
\hline 1 & $\begin{array}{c}\text { Sujek sudah } \\
\text { memahami apa } \\
\text { yang dimaksud } \\
\text { dari butir soal } \\
\text { dengan baik }\end{array}$ & $\begin{array}{l}\text { Siswa sudah bisa } \\
\text { memahami maksud } \\
\text { dari pertanyaan }\end{array}$ & $\begin{array}{l}\text { Siswa sudah dapat } \\
\text { menjawab } \\
\text { pertanyaan dengan } \\
\text { hasil yang benar dan } \\
\text { tepat }\end{array}$ \\
\hline 2.1 & $\begin{array}{c}\text { Sujek sudah } \\
\text { memahami apa } \\
\text { yang dimaksud } \\
\text { dari butir soal } \\
\text { dengan baik dan } \\
\text { menjawab dengan } \\
\text { benar tetapi tidak } \\
\text { menuliskan } \\
\text { kesimpulan akhir }\end{array}$ & $\begin{array}{c}\text { Siswa lupa } \\
\text { menuliskan } \\
\text { kesimpulan akhir } \\
\text { dari jawabannya }\end{array}$ & $\begin{array}{c}\text { Ia sudah bisa } \\
\text { menggambarkan apa } \\
\text { yang dibutuhkan } \\
\text { untuk } \\
\text { mempermudahnya } \\
\text { dalam proses } \\
\text { penyelesaian }\end{array}$ \\
\hline 2.2 & $\begin{array}{c}\text { Siswa sudah } \\
\text { mengerjakan soal } \\
\text { dengan baik dan } \\
\text { benar hanya saja } \\
\text { tidak menuliskan } \\
\text { apa yang ditanya } \\
\text { dan tidak } \\
\text { menuliskan } \\
\text { kesimpulan }\end{array}$ & $\begin{array}{c}\text { Subjek tidak } \\
\text { menuliskan apa } \\
\text { yang ditanyakan } \\
\text { dan tidak } \\
\text { menuliskan } \\
\text { kesimpulan }\end{array}$ & $\begin{array}{l}\text { Siswa sudah dapat } \\
\text { menjawab } \\
\text { pertanyaan dengan } \\
\text { hasil yang benar dan } \\
\text { tepat }\end{array}$ \\
\hline 3.1 & $\begin{array}{c}\text { Subjek penelitian } \\
\text { kurang teliti pada } \\
\text { proses } \\
\text { penyelesaian } \\
\text { masalah dan tidak } \\
\text { menuliskan } \\
\text { kesimpulan }\end{array}$ & $\begin{array}{l}\text { Subjek terburu- } \\
\text { buru untuk } \\
\text { menyelesaikan } \\
\text { butir soal ini } \\
\text { sehingga kurang } \\
\text { sempurna dalam } \\
\text { beberapa tahap }\end{array}$ & $\begin{array}{l}\text { Siswa sudah dapat } \\
\text { menjawab } \\
\text { pertanyaan dengan } \\
\text { hasil yang benar dan } \\
\text { tepat }\end{array}$ \\
\hline 3.2 & $\begin{array}{c}\text { Siswa tidak } \\
\text { menuliskan tahap } \\
\text { penyelesaian } \\
\text { masalah dan tidak } \\
\text { menuliskan } \\
\text { kesimpulan }\end{array}$ & $\begin{array}{l}\text { Subjek tidak bisa } \\
\text { menjelaskan apa } \\
\text { yang ia maksud di } \\
\text { dalam pekerjaannya } \\
\text { walaupun ia } \\
\text { mengerti }\end{array}$ & $\begin{array}{c}\text { Siswa sudah dapat } \\
\text { menjawab } \\
\text { pertanyaan dengan } \\
\text { hasil yang benar dan } \\
\text { tepat }\end{array}$ \\
\hline
\end{tabular}


Tabel 4 Hasil Triangulasi dari Subjek Penelitian II

\begin{tabular}{|c|c|c|c|}
\hline $\begin{array}{l}\text { Butir } \\
\text { Soal }\end{array}$ & $\begin{array}{c}\text { Hasil Analisis } \\
\text { Tes }\end{array}$ & $\begin{array}{c}\text { Hasil Analisis } \\
\text { Wawancara }\end{array}$ & $\begin{array}{c}\text { Hasil Analisis } \\
\text { Observasi }\end{array}$ \\
\hline 1 & $\begin{array}{c}\text { Siswa tidak } \\
\text { menuliskan } \\
\text { informasi yang } \\
\text { ada pada butir soal }\end{array}$ & $\begin{array}{c}\text { Siswa tidak } \\
\text { menuliskan } \\
\text { informasi yang ia } \\
\text { dapat }\end{array}$ & $\begin{array}{c}\text { Ia sudah bisa } \\
\text { menggambarkan apa } \\
\text { yang dibutuhkan } \\
\text { untuk } \\
\text { mempermudahnya } \\
\text { dalam proses } \\
\text { penyelesaian }\end{array}$ \\
\hline 2.1 & $\begin{array}{c}\text { Siswa tidak } \\
\text { menuliskan } \\
\text { informasi yang } \\
\text { ada pada butir soal } \\
\text { dan tidak } \\
\text { menuliskan } \\
\text { kesimpulan }\end{array}$ & $\begin{array}{c}\text { Siswa tidak } \\
\text { menuliskan } \\
\text { informasi yang ia } \\
\text { dapat dikarenakan } \\
\text { ia melupakannya }\end{array}$ & $\begin{array}{c}\text { Ia belum bisa } \\
\text { menggambarkan apa } \\
\text { yang dibutuhkan } \\
\text { untuk } \\
\text { mempermudahnya } \\
\text { dalam proses } \\
\text { penyelesaian }\end{array}$ \\
\hline 2.2 & $\begin{array}{c}\text { Siswa tidak } \\
\text { menuliskan } \\
\text { informasi yang } \\
\text { ada pada butir soal } \\
\text { dan salah dalam } \\
\text { menghitung hasil } \\
\text { perkaliannya }\end{array}$ & $\begin{array}{c}\text { Ia mengalami } \\
\text { kesulitan dalam } \\
\text { mengubah satuan } \\
\text { dikarenakan } \\
\text { subjek lupa dan } \\
\text { belom memahami } \\
\text { cara } \\
\text { mengubahnya }\end{array}$ & $\begin{array}{c}\text { Siswa menyelesaikan } \\
\text { soal ini pada saat } \\
\text { berlangsungnya tes }\end{array}$ \\
\hline 3.1 & $\begin{array}{c}\text { Siswa tidak } \\
\text { menuliskan } \\
\text { informasi yang } \\
\text { ada pada butir soal } \\
\text { dan tidak } \\
\text { menuliskan } \\
\text { kesimpulan }\end{array}$ & $\begin{array}{c}\text { Siswa tidak } \\
\text { menuliskan } \\
\text { informasi yang } \\
\text { ada pada soal dan } \\
\text { langsung } \\
\text { menjawab soal } \\
\text { tersebut }\end{array}$ & $\begin{array}{c}\text { Ia sudah bisa } \\
\text { mengambarkan apa } \\
\text { yang dibutuhkan } \\
\text { untuk mempermudah } \\
\text { nya dalam proses } \\
\text { penyelesaian }\end{array}$ \\
\hline 3.2 & $\begin{array}{c}\text { Siswa tidak } \\
\text { menjawab } \\
\text { pertanyaan yang } \\
\text { ada pada soal }\end{array}$ & $\begin{array}{l}\text { Siswa tidak bisa } \\
\text { mengerjakan butir } \\
\text { soal ini }\end{array}$ & $\begin{array}{c}\text { Siswa tidak } \\
\text { memahami apa yang } \\
\text { dimaksud dari } \\
\text { pertanyaan yang ada }\end{array}$ \\
\hline
\end{tabular}


$\begin{array}{rcr}\text { Kesulitan- } & \text { kesulitan yang } \\ \text { dialami oleh } & \text { siswa }\end{array}$ menyelesaikan soal matematika model PISA dikarenakan siswa masih belum terlalu mengerti dengan materi apa yang dipertanyakan pada soal. Kesulitan siswa dalam menyelesaikan soal PISA berbeda- beda khususnya ketika menyelesaikan soal cerita. Siswa dengan kemampuan pemecahan masalah tinggi lebih memahami soal yang diberikan sedangkan siswa dengan kemampuan pemecahan masalah sedang, sedikit mengalami kesulitan di penulisan akhir dan cendrung terburu-buru ketika menjawab, dan siswa dengan kemampuan pemecahan masalah rendah, lebih sulit memahami soal dan lebih tidak teliti ketika menjawab pertanyaan sehingga menyebabkan ia salah dalam menjawab soal. Dalam kegiatan belajar mengajar, guru ketika menyampaikan pelajaran tentang soal matematika khususnya pelajaran aljabar, hendaknya guru melibatkan seluruh siswa agar ikut aktif dalam proses pembelajaran, sehingga kemampuan pemecahan masalah siswa dapat terlatih dan dapat ditingkatkan agar siswa tidak kesulitan ketika menjawab soal khususnya soal PISA.

\section{SIMPULAN DAN SARAN}

\section{Kesimpulan}

Dari hasil analisis yang
diperoleh dapat dikatakan siswa
dengan kemampuan pemecahan
masalah tinggi lebih dapat memahami
soal yang diberikan dan menjawab

semua pertanyaan dengan baik dan benar. Siswa dengan kemampuan pemecahan masalah sedang menjawab dengan benar hanya saja ia kurang teliti ketika tidak memberikan kesimpulan dan dalam beberapa soal ia tidak mem berikan informasiinformasi yang ada pada soal. Dan siswa yang memiliki kemampuan pemecahan rendah cendrung ingin menjawab pertanyaan dengan cepat sehingga tidak menuliskan informasi yang ada pada soal dan tidak teliti ketika mengerjakan soal sehingga menyebabkan kesalahan ketika menjawab soal.

\section{Saran}

Bagi guru matematika, agar dapat mengunakan soal- soal bertipe PISA sebagai alternatif dalam memperkaya variasi pemberian soal matematika untuk melatih pemecahan masalah siswa

Bagi siswa, agar termotifasi untuk mengerjakan soal- soal yang membiasakan diri untuk mengembangkan kemampuan pemecahan masalah dalam hal mengidentifikasi suatu permasalahan dan menyatakan kembali suatu permasalahan dalam bentuk yang lebih mudah untuk mencari penyelesian melalui latihan- latihan soal 


\section{RUJUKAN}

Bickel, W. E. (1999). The implications of the effective schools literature for school restructuring. In C. $R$. Reynolds \& T. B. Gutkin (Eds.), The handbook of school. New York: John Wiley \& Sons, Inc.

Budiyono. (2003). Statistik Untuk Penelitian. Surakarta: Sebelas Maret University.

Cai, J., \& Steven, H. (t.thn.). Generalized and Generative Thinking in U.S and Chinese Students' Mthematical Problem Solving and Problem Posing. Journal of mathematical Behavior, 21, 401-21.

Chall, J. S. (2000). The academic achievement challenge: What really works in the classroom? New York: Guilford Press.

Delic, H., \& Becirovic, S. (2016). Socratic Method as an Approach to Teaching. European Researcher, 111, 511-517.

Douglas, R. O. (2014). The Fact of Ignorance: Revisiting the Socratic Method as a Tool for Teaching Critical Thinking. American Journal of Pharmaceutical Education .

Edward, A. S., \& Jinfa, C. (2005). Assessing students' mathematical problem posing. Teaching Children Mathematic, 12(3) , 129-135.

Gettinger, M., \& Stoiber, K. C. (1999). Excellence in teaching: Review of instructional and environmental variables. In $C$. R. Reynolds \& T. B. Gutkin (Eds.), The handbook of school psychology. New York: John Wiley \& Sons, Inc.

Lam, F. (2011). The Socratic Method as an Approach to Learning and Its Benefits. Dietrich College of Humanities and Social Sciences

Limakrisna, N., \& Supranto. (2013). Petunjuk Praktis untuk Menyusun Skripsi, Tesis, dan Disertasi, Edisi 3. Jakarta: Mitra Wacana Media.

Magen, N. (2016). The Efect of Learning Srategies on Mathematical Literacy: A Comparasion Between Lower or Higher Achieving Countries. International Journal of Research in Education and Science, 2(2), 306-321.

Mahdiansah, \& Rahmawati. (2014). Mathematical Literacy of Students at Secobdary Education Level: An Analysis Using International Test Design with Indonesian Context. Jurnal Pendidikan dan Kebudayaan, Vol. 20, Nomor 4 .

Marilyn, B. (2000). About Teaching Mathematics. Math Solutioan Publications .

Mujulifah. (2015). Literasi Matematis Siswa dalam Menyederhanakan Eksspresi Aljabar. Jurnal Pendidikan dan Pembelajaran, Vol 4, Nomor 1 .

Novalia, \& Syazali, M. (2014). Olah Data Penelitian Pendidikan. Bandar Lampung: AURA.

OECD. (2015). Data Base Indonesia. OECD Publisher. 
Pahlavi, S. R. (2014). Pengaruh Metode Socrates dalam Pembelajaran Bangun Datar Terhadap Kemampuan Berpikir Kritis Siswa Kelas VII. Satya Wacana, 28-33.

Paraskevas, A., \& Wickens, E. ( 2007). Andragogy and the Socratic Method: the Adult Learner Perspective. Journal of Hospitality, Leisure, Sport \& Tourism Education , 4-14.

Parsian, A. (2011). Motivate the Minds of Students in Mathematics. Proceeding of first Mathematical Development (hal. 9). Iran: Education and Innovations Conference (MDEIC).
Parsian, A. (2014). Deep Learning in Mathematics through SGT Method. Journal of Basic and applied Scientific Research, 4 (4) , 184-189.

Smith, M. S., \& Mary, K. S. (1998). Selecting and creating mathematical tasks: From research to practice. Mathematics Teaching in the Middle School, 3, 344-50 .

Wulansari, N., Yunarti, T., \& M. Coesamin. (2013). Penerapan Metode Socrates Melalui Pendekatan Kontekstual pada Pembelajaran Matematika. Jurnal FKIP Unila . 
